\title{
La concepción nietzscheana de la vida, su limitación por el lenguaje y su influencia en Agamben y Esposito.
}

\author{
Franco Revidatti Turpín \\ Estudiante de la Licenciatura en Filosofía \\ Universidad Nacional del Nordeste \\ francorevi@gmail.com
}

\section{Resumen}

El tema de la vida en Nietzsche es recurrente en toda su obra, si bien por el estilo de su filosofía nunca se detuvo a definirla, sino que más bien se debe realizar un análisis de su pensamiento para lograr comprenderla. De esta manera es que se la entiende como el devenir, en el cual se ponen en juego el eterno retorno y la voluntad de poder. Para Nietzsche es imposible realizar una conceptualización de la vida, ya que al hacerlo, en realidad la estamos limitando. Según dicho filósofo, el ser humano inventa palabras allí donde el entendimiento no llega, donde se deja de comprender o conocer. Teniendo en cuenta esto, es que se llega a la idea de que por fuera del lenguaje nada es posible de ser pensado. Toda división, segmentación o conceptualización no es más que introducir límites o intentar retener aquello que el autor plantea como vida humana, que es simplemente un flujo continuo que no se puede definir con palabras. Esta misma dificultad de poder definir la vida se puede encontrar en los filósofos de la biopolítica, entre los que podemos encontrar a Agamben y a Esposito. Para Agamben, la dificultad de expresar el significado de vida viene ya desde los griegos, con la diferenciación que utilizan de algunos términos, teniendo en cuenta que el lenguaje es únicamente propio y característico de la vida humana. Mientras que para Esposito, por otra parte, la vida está inmersa en el ámbito político, el cual sólo es posible gracias al lenguaje.

Palabras claves: Nietzsche, Vida, Lenguaje, Biopolítica, Voluntad de Poder. 


\section{Abstract}

The theme of life in Nietzsche is recurrent throughout his work, although by the style of his philosophy he never stopped to define it, but rather an analysis of his thought must be made in order to understand it. In this way it is understood as the becoming, in which the eternal return and the will to power are put into play. For Nietzsche, it is impossible to conceptualize life, since in doing so, we are actually limiting it. According to said philosopher, the human being invents words where the understanding does not arrive, where it stops understanding or knowing. Taking this into account, it is that you get to the idea that outside of language nothing is possible to be thought. Any division, segmentation or conceptualization is nothing more than introducing limits or trying to retain what the author raises as human life, which is simply a continuous flow that can not be defined with words. This same difficulty of being able to define life can be found in the philosophers of biopolitics, among which we can find Agamben and Esposito. For Agamben, the difficulty of expressing the meaning of life comes from the Greeks, with the differentiation they use from some terms, taking into account that language is uniquely characteristic of human life. While for Esposito, on the other hand, life is immersed in the political sphere, which is only possible thanks to language.

Keywords: Nietzsche, Life, Language, Biopolitics, Will to power.

\section{Introducción}

El trabajo de investigación que se llevará adelante comenzará por desarrollar el concepto de vida en Nietzsche, teniendo en cuenta que para el autor es imposible realizar una conceptualización de la misma, ya que al hacerlo, en realidad la estamos limitando. Según dicho filósofo, el ser humano inventa palabras allí donde el entendimiento no llega, donde se deja de comprender o conocer. Teniendo en cuenta esto, es que se arriba a la idea de que por fuera del lenguaje nada es posible de ser pensado. Toda división, segmentación o conceptualización no es más que introducir límites o intentar retener aquello que el autor plantea como vida, que es simplemente un flujo continuo que no se puede definir con palabras. Y aquí se plantea el problema 
de cómo lograr hacer filosofía sin limitar aquel flujo, sin poner divisiones que se originan únicamente en el intelecto humano.

De esto se desprende el hecho de que, los biopolíticos con los que se trabajará aquí, intentan desarrollar sus concepciones de vida y su relación con la política y el derecho, pero tal vez descuidando esto que sostenía Nietzsche o bien teniendo otra definición de lenguaje y de su alcance. Sin embargo se enfocan y llevan adelante el intento de poder definir la vida, para desarrollarla y sumergirla dentro de su filosofía. Estos pensadores de la biopolítica en los cuales nos abocaremos serán los italianos Giorgio Agamben y Roberto Esposito. Ambos autores contemporáneos realizan sus investigaciones y trabajos en el campo de la biopolítica, y por lo tanto siguen las líneas que Foucault comenzó al introducirse en esta problemática, aunque también han llegado a posturas que se diferencian de las del filósofo francés. Lo importante para este trabajó será no perder de vista el campo que se está investigando, con la particularidad que el enfoque aquí se dará desde una crítica sostenida por la noción de lenguaje que maneja Nietzsche, es decir, el de límite de la vida. Para Agamben, la dificultad de expresar el significado de vida viene ya desde los griegos, con la diferenciación que utilizan de algunos términos, teniendo en cuenta que el lenguaje es únicamente propio y característico de la vida humana. Mientras que para Esposito, por otra parte, la vida está inmersa en el ámbito político, el cual sólo es posible gracias al lenguaje, y que a su vez es la política la que debe garantizar la inmunización de la vida de la comunidad, para que esta sobreviva.

Planteada así la dificultad de este tema, pareciera que esta investigación es necesaria en la filosofía por el motivo de que Nietzsche plantea que el lenguaje no hace más que engañar y mentir al hombre, pero al mismo tiempo sin él no es capaz ni siquiera de pensar o de imaginarse cosas. Es decir que sin el lenguaje la filosofía misma no sería posible. Ahora bien, si la vida es un continuo fluir no podría ser dominada. Por esto mismo es importante dilucidar el tema, intentar comprender las concepciones nietzscheanas de vida y lenguaje para lograr enmarcarlos dentro de los nuevos pensamientos sobre biopolítica de Agamben y Esposito. De esta manera también comprender las concepciones de vida que poseen dichos autores, y si es que estos se 
basan en el continuo flujo nietzscheano, que no es posible de ser apresado, o más bien dejan de lado esta noción para introducir sus propias perspectivas.

Por todo lo planteado, en esta investigación se trabajará con la hipótesis de que la concepción nietzscheana de la vida es un flujo continuo imposible de ser segmentando en ninguno de sus ámbitos, debiendo ser retirado el lenguaje de ella, puesto que operaría como un límite más a ese flujo. Pero al mismo tiempo es el lenguaje la herramienta que poseen los filósofos biopolíticos para definir la vida que se pone en juego en la población. Entonces la propuesta del trabajo será la de desarrollar la concepción de vida en Nietzsche para lograr determinar cuál es la importancia dentro de su pensamiento filosófico y qué impronta dejó para la filosofía posterior. También se intentará demostrar que el lenguaje opera como un límite para la vida según la concepción nietzscheana, puesto que intenta delimitarla y apresarla, sin dejar que se exprese según su voluntad; además de examinar si esta concepción nietzscheana de la vida se encuentra presente o tiene alguna influencia en las concepciones de vida de los filósofos de la biopolítica contemporánea.

Para lograr estos propósitos se busca una reconstrucción de los conceptos utilizados en el presente trabajo, y así clarificar la postura de cada autor al ser empleados. Esto se llevó adelante a través de la selección del material bibliográfico y del fichaje correspondiente, así como la realización de las conceptualizaciones en cada caso.

Siendo que es necesario partir de Nietzsche y de su idea sobre la vida, el trabajo comenzará por desarrollar sus conceptos principales, entendiendo a la vida como devenir, tal como lo plantea el filósofo alemán, siendo que allí hay dos aspectos que se ponen en juego de manera constante: la voluntad de poder y el eterno retorno. Ya en una segunda parte el tema versará sobre el lenguaje como límite de esa vida, y del engaño que el intelecto puede tender al hombre. Por último se hará un breve recorrido de la biopolítica y sus características principales, para luego trabajar con los conceptos de vida en Agamben y Esposito, y así examinar qué relación se encuentra con la vida en Nietzsche. 


\section{Concepción nietzscheana de la vida}

Podríamos afirmar que a lo largo de toda la obra de Nietzsche se encuentra el problema de la vida, como tema de suma importancia dentro de su pensamiento. En reiteradas ocasiones recurre a él; vuelve una y otra vez desde distintas perspectivas, pero siempre sosteniendo que la vida del hombre es efímera y se encuentra sumida en un sinsentido, por más que el mismo ser humano se esfuerce en buscarlo para afirmar que allí se encuentra la felicidad. Esto no es más que un engaño del intelecto, el cual intentaremos ir desenredando más adelante. Lo importante es comprender que para este filósofo la vida no tiene un fin o una meta en la cual se encuentra la felicidad.

Una de las primeras complicaciones que se plantea al investigar el pensamiento de un filósofo como Nietzsche, es que no hay una definición exacta o una conceptualización de lo que para el autor significa la vida, sino que más bien va hablando de ella en varios pasajes de sus escritos, va desarrollando su pensamiento en lo que a ella respecta pero sin intención de ofrecer una definición. Esto se da en parte por el concepto que el mismo filósofo posee del lenguaje, el cual utilizamos para ofrecer las definiciones.

Como se dijo, la vida no tiene un fin ni una meta, no tiene un sentido hacia el cual debe orientarse el actuar humano. "Todo nuestro actuar y conocer no es ninguna sucesión de hechos e intervalos vacíos, sino un flujo continuo" ${ }^{26}$. Con esto Nietzsche pretende poner fin a la visión de la vida como una línea recta, donde hay un principio y un final de la misma, sino que más bien es algo circular, en donde lo que prevalece es el devenir. La vida de esta manera termina de ser algo lineal, y por lo tanto algo inmutable, estable y pasivo, para convertirse en el cambio, en la transformación y lo activo. "Aún continúa viviendo la ancestral ilusión de que sabemos, de que sabemos exactamente, cómo se produce el actuar humano, en todos los casos posibles" ${ }^{27}$. El devenir es esto, mutación y dinamismo. El filósofo adquiere esta nueva concepción de la vida donde prevalece el devenir, donde se esperan cambios frente a la realidad actual.

\footnotetext{
${ }^{26}$ NIETZSCHE, Friedrich. Humano, Demasiado Humano II. El Viajero y su Sombra y Opiniones y Sentencias. Madrid, Akal, 2007 p. 120.

${ }^{27}$ NIETZSCHE, Friedrich. Aurora, Madrid, Edaf, 1996, p. 166.
} 
De esta manera el devenir plantea una nueva realidad, una en la cual de nada sirve permanecer de forma pasiva frente a los sucesos, sino más bien conviene adquirir una postura activa. Y justamente en esta realidad, en el devenir, adquieren especial importancia dos aspectos que Nietzsche desarrolla en sus escritos, sin detenerse a conceptualizar, pero si recurriendo varias veces a ellos. Estas dos características son el eterno retorno y la voluntad de poder, los cuales se desarrollarán a continuación, ya que forman parte de este devenir, de este fluir constante que no tiene fin.

\subsection{La voluntad de poder}

Cuando Nietzsche menciona la voluntad de poder, no lo hace en referencia a un sentido psicológico, sino más bien a algo biológico y orgánico, en relación a demostrar su vitalidad y de allí su fuerza. Debe ser entendida la voluntad de poder en función de lo que es la vida, aunque esto no implica que sea la vida concretamente. Sino que la voluntad de poder es siempre algo más, busca superarse e ir por más, es una fuerza que intenta transformar constantemente.

Anteriormente se afirmó que Nietzsche comprende a la vida de forma activa, como devenir constante. Pues bien, la voluntad de poder es esa fuerza que da la posibilidad de llevarlo adelante, de realizar esas mutaciones. En todo viviente se da esta voluntad a través de una misma base que relaciona dos acciones, la de mandar o la de obedecer. Al que no sabe obedecerse a sí mismo se le dan órdenes. En este sentido es más fácil obedecer que mandar, y los es por tres motivos: porque quien manda lleva el peso de quienes lo obedecen, lo que lo puede aplastar; porque al mandar se arriesga a sí mismo; y porque quien manda tiene que ser a la vez juez, vengador y víctima de su propia ley ${ }^{28}$. Sin embargo todos quieren mandar, pues eso es la voluntad, ese es el deseo de todo viviente, inclusive de los débiles que obedecen a los fuertes, pues ellos quieren imponerse sobre aquellos que son más débiles aún. Por eso la voluntad de poder es una lucha, un enfrentamiento en el cual uno se quiere imponer al otro, hacerlo sumiso y dominarlo.

\footnotetext{
${ }^{28}$ Cfr. NIETZSCHE, Friedrich. Así habló Zaratustra. Madrid, Alianza, 2003.
} 
Pero la voluntad de poder no es la fuerza del más fuerte que se impone sobre los débiles, sino más bien de aquellos hombres que son creadores, que no se detienen a soportar el peso de otros vivientes. Por lo tanto es la voluntad de lo que Nietzsche llama superhombre, aquel que supera, que va más allá de la mera supervivencia, más allá de la vida tal cual se la conoce ahora, para crear y transformar, para imponer su voluntad de poder. Ésta misma está oculta en la realidad; esa realidad que antes definimos como dinámica y en constante mutación. Y esta voluntad va más allá de la autoafirmación del viviente, sobrepasa la voluntad de vivir, es decir el deseo propio de cada viviente por conservar su vida. La voluntad de poder, en cambio, da un paso más y su fuerza supera la actividad individual, sosteniéndose en la realidad que está de fondo.
Los fisiólogos deberían pensárselo bien antes de afirmar que el instinto de autoconservación es el instinto cardinal de un ser orgánico. Algo vivo quiere, antes que nada, dar libre curso a su fuerza -la vida misma es voluntad de poder-: la autoconservación es tan sólo una de las consecuencias indirectas y más frecuentes de esto. ${ }^{29}$

Allí queda bien marcada por el filósofo la diferencia entre la autoconservación y la voluntad de poder. La primera es sólo una consecuencia indirecta de la fuerza vital, pero no es aquello que lo mueve, que motiva. Sino que lo que todo viviente quiere es poder desplegar a su placer la fuerza que trae consigo, el dominar a otros y de esta manera poder crear.

\subsection{El eterno retorno}

La idea en sí del eterno retorno es algo que ya estaba presente en los inicios de la filosofía con los griegos, más precisamente fue Heráclito quien desarrolló su pensamiento en torno a esta idea. Nietzsche retoma el concepto pero claramente le da una nueva impronta, más profunda y compatible con su pensamiento filosófico.

\footnotetext{
${ }^{29}$ NIETZSCHE, Friedrich. Más allá del bien y del mal. Madrid, Alianza, 2005, pp. 36-37.
} 
Anteriormente habíamos dicho que Nietzsche critica la idea lineal del tiempo, y plantea la mutación y el cambio que son el devenir. Esta idea de tiempo viene principalmente del cristianismo, a quien Nietzsche se dedicó a criticar duramente. Por esto es que también retoma una idea anterior a esa religión, y propone el eterno retorno como la solución. Con esto afirma que no hay un inicio, desarrollo y final del tiempo como lo conocemos, sino más bien lo contrario, es decir un circulo sin distinción de sus momentos.

Para Nietzsche, el tiempo es infinito, pero no así la materia, de la cual se sabe que es finita. Por lo tanto, todas las cosas, seres y sucesos se deben repetir en el tiempo una y otra vez, puesto que éste nunca se ha de acabar. Así plantea la teoría del eterno retorno. En La ciencia jovial introduce una suposición donde un demonio se aparece y dice: "Esta vida, así como la vives ahora y la has vivido, tendrás que vivirla una vez más e innumerables veces más; y nada nuevo habrá alli” ${ }^{30}$. Todo lo que se ha vivido se volverá a vivir exactamente igual a como ha sucedido. De esta manera se podría preguntar si la vida de los seres humanos está predestinada y nada se puede evitar o cambiar. Y si, siendo de esta manera, carece de valor o pierde cualquier prestigio que pudiera tener. Pero no sólo la vida humana, sino la de cualquier ser viviente que exista, puesto que no sería más que una repetición de lo que ya ha sucedido y de lo que sucederá en adelante, sin importar lo que uno haga.

Lejos de desprestigiar la vida con esta idea, Nietzsche logra colocarla en un lugar de privilegio. Según el autor no hay nada trascendente en el mundo, ni cree en una vida más allá de esta, sino que asegura que ésta misma vida se repetirá infinitamente en el tiempo, por lo tanto, es necesario amar verdaderamente esta vida y disfrutarla, puesto que todas las situaciones, actos, dolores, sufrimientos y alegrías serán vividas infinidad de veces. Así podríamos afirmar que Nietzsche termina por poner a la vida por sobre el resto de las cosas, ya que sólo ésta tiene sentido de ser abrazada y gozada, pues se repetirá por siempre. Seguido a la frase citada en el párrafo anterior, Nietzsche sostiene que

\footnotetext{
${ }^{30}$ NIETZSCHE, Friedrich. La ciencia jovial. Caracas, Monte Avila Editores, 1990, p. 200.
} 
Si aquel pensamiento llegara a tener poder sobre ti, así como eres, te transformaría y tal vez te trituraría; frente a todo y en cada caso, la pregunta: «¿quieres esto una vez más e innumerables veces más?», irecaería sobre tu acción como la mayor gravedad! ¿O cómo tendrías que llegar a ser bueno contigo mismo y con la vida, como para no anhelar nada más sino esta última y eterna confirmación y sello ${ }^{31}$.

Es decir que, al lograr comprender el eterno retorno, al comprender que la vida se repetirá tal cual una y otra vez sin alteración, lo único que le queda al hombre es amarla y disfrutarla de manera plena. Y por lo tanto amarse a sí mismo, puesto que es uno el que vivirá los instantes de manera infinita, y nadie más que él. Pero este amar la vida se traduce en vivirla cumpliendo la propia voluntad de poder, es decir deseando imponerla frente a los demás, queriendo que se realice tal cual se le presenta al hombre, y de esta manera ser creador y no un simple oprimido. Si la vida se ha de repetir infinidad de veces, lo oportuno sería que el hombre lleve adelante su voluntad y no la de otro, pues de lo contrario sería para siempre un cordero dominado por otras personas en vez de llevar adelante su propia voluntad de poder.

El devenir de la vida consiste en esto, en el eterno retorno donde las cosas se suceden infinidad de veces, y donde el hombre debe lograr imponer su propia voluntad de poder para asegurarse de gozar ahora y en las repeticiones infinitas que vendrán. La vida de esta manera adquiere un carácter primordial dentro de la filosofía de este autor, si bien nunca la definió concretamente ni realizó un concepto detallado de la misma, sino que fue girando en torno a su problemática.

\section{El lenguaje como límite de la vida}

Habiendo desarrollado el tema de la vida según Nietzsche, se llega ahora a uno de los puntos centrales del presente trabajo, donde se quiere plasmar cómo el lenguaje es un condicionante de esta vida y a la vez un claro límite para su expresión. Toda la vida humana está cercada por el lenguaje, sin él no se podría expresar el ser

\footnotetext{
${ }^{31}$ NIETZSCHE, Friedrich. La ciencia jovial. Op. cit., p. 200.
} 
humano, pero al mismo tiempo no hay manera de hacerlo por fuera del mismo, ni siquiera sería posible pensar.

Nietzsche sostiene que es el lenguaje el causante de que el hombre se engañe en cuanto a cómo suceden los hechos ${ }^{32}$. Para el filósofo alemán no hay una división entre causa y efecto, ni una sucesión temporal en nuestro actuar, sino que todo es un flujo continuo; pero es por el lenguaje que se introducen las divisiones e intervalos, ya que a ese flujo continuo se lo corta para definirlo con conceptos y palabras, lo que genera la mentira de creer que son hechos aislados. Además, por el lenguaje, le adjudicamos ciertos caracteres y jerarquía a esos hechos, y así se los agrupa según su 'semejanza'; pero nuevamente esto no es más que un error producto de nuestra manera de utilizar el lenguaje, del cual no podemos escapar. De la misma forma que se conceptualizan los hechos y el actuar del hombre, así mismo se lo hace con los instintos interiores, a los cuales el hombre le pone nombre y los delimita, prestando mayor importancia a aquellos que Nietzsche llama estados extremos ${ }^{33}$, los cuales sólo arrebatan al ser humano en un momento determinado, pero luego es el mismo flujo continuo en el cual se desenvuelve su vida. El problema está en que sólo se toma conciencia de esos momentos que rasgan la tela, y es por ello que se le pone nombre específicos, ya que para el filósofo el hombre deja de observar allí donde no tiene palabras para nombrar. Por esto sostiene que el lenguaje es un error y engaño de la modernidad, puesto que no se presta atención allí donde transcurre el flujo continuo, sino en aquello que causa exabruptos.

Siguiendo este mismo punto de vista, Nietzsche critica aquellas oportunidades que se utiliza la palabra querer, puesto que allí se designa un deseo que el hombre cree poder saciar gracias a la libertad que posee ${ }^{34}$. Pero nuevamente esto no es más que un error, una mentira que el lenguaje opera en el ser humano. Puesto que la simple palabra querer es sólo una invención del lenguaje, el cual hace creer a través de la conciencia que el hombre es un sujeto libre y que le es lícito el querer; cuando en realidad lo que sucede no se puede evitar. Ahora bien, el hombre no acepta esto, y por

\footnotetext{
${ }^{32}$ Cfr. NIETZSCHE, Friedrich. Humano, Demasiado Humano II. El Viajero y su Sombra y Opiniones y Sentencias. Op. cit.

${ }^{33}$ Cfr. NIETZSCHE, Friedrich. Aurora. Op. cit.

${ }^{34}$ Cfr. NIETZSCHE, Friedrich. Aurora. Op. cit.
} 
lo tanto se convence de que es libre y de que puede hacer lo que quiere. Esto no es más que una invención, así como tantas otras palabras que el hombre introduce en su vida por el simple hecho de que no logra ver o entender ${ }^{35}$. Por esto Nietzsche sostiene que allí donde ya no se ve, el ser humano introduce palabras y las toma por verdades, cuando en realidad no son más que mero lenguaje, un simple engaño que se hace para que se sienta bien consigo mismo, para creer que es libre y que puede realizar aquello que dice y se propone. Donde ya no es consciente el hombre, donde ya no logra ver más, allí se hace presente el lenguaje, allí se introducen palabras y conceptos que lo tranquilizan, que lo hacen sentir seguro por las verdades que transmiten.

Para Nietzsche el intelecto humano "sólo ha sido añadido precisamente como un recurso de los seres más infelices, delicados y efímeros, para conservarlos un minuto en la existencia" ${ }^{\prime 36}$. Sin ésta herramienta, el hombre no podría haber sobrevivido en la naturaleza frente a los demás seres vivos. Es decir que es un recurso que posee para enfrentar las adversidades, así como algunos otros seres tienen garras o colmillos, el hombre posee intelecto. Pero como se describió anteriormente éste nos engaña continuamente. Y la mayor de las mentiras que hace, es la de creer que se puede alcanzar la verdad, puesto que hay cierto impulso que lo lleva al hombre hacia ella. Ahora bien, ese impulso a la verdad procede del hecho de que es necesario para el humano vivir en sociedad, y para lograrlo es conveniente llegar a un cierto tratado de paz para convivir. Dicho tratado consiste justamente en fijar "lo que a partir de entonces ha de ser 'verdad', es decir, se ha inventado una designación de las cosas uniformemente válida y obligatoria, y el poder legislativo del lenguaje proporciona también las primeras leyes de verdad”37. Es decir que los hombres se ponen de acuerdo sobre a qué se llamará verdad para poder vivir en sociedad y qué será la mentira o lo inválido, aquello que no está permitido hacer. Para arribar a ello nuevamente aparece el lenguaje, pues éste brinda las herramientas lógicas para fijar esos conceptos o leyes en una estructura coherente.

\footnotetext{
${ }^{35}$ Cfr. NIETZSCHE, Friedrich. La voluntad de poder. Madrid, Edaf, 2000.

${ }^{36}$ NIETZSCHE, Friedrich. Sobre verdad y mentira en sentido extramoral. Madrid, Tecnos, 1998, p 18.

${ }^{37}$ NIETZSCHE, Friedrich. Sobre verdad y mentira en sentido extramoral. Op. cit., p. 20.
} 
Con esto Nietzsche quiere decir que el lenguaje no es la manera de expresar la cosa en sí, la realidad misma. Más bien es la forma que tiene el hombre para expresar su perspectiva, pero cada uno de los animales tendrá una mirada diferente de cada hecho, cosa o suceso. Y es más, entre los mismos hombres hay diferentes perspectivas dependiendo del lenguaje que utilice cada uno. "Los diferentes lenguajes, comparados unos con otros, ponen en evidencia que con las palabras jamás se llega a la verdad ni a una expresión adecuada pues, en caso contrario, no habría tantos lenguajes ${ }^{\prime 38}$. Si hay tanta variedad de lenguajes tan diferentes, no es posible que sea a través de las palabras que se llegue a la cosa en sí.

Siguiendo con la crítica que realizó, Nietzsche sostiene que los conceptos se forman "al abandonar de manera arbitraria esas diferencias individuales, al olvidar las notas distintivas, con lo cual se suscita entonces la representación, como si en la naturaleza hubiese algo separado [...], una especie de arquetipo primigenio" ${ }^{39}$. Pero el filósofo afirma que esto no es así, que no existe ese arquetipo primigenio, y que se comente un error al buscar sacar las diferencias entre objetos similares, intentando encontrar algo en lo que coincidan, definiendo a partir de esa característica a la cosa en sí. No existe algo desde donde se pueda definir a todo un grupo de cosas y formar un género. Esto es un nuevo engaño del intelecto. Lo único que existe son esas individualidades presentes en las cosas. "La naturaleza no conoce formas ni conceptos, así como tampoco ningún tipo de géneros, sino solamente una x que es para nosotros inaccesible e indefinible ${ }^{\prime 40}$.

La naturaleza, y dentro de ella la vida, no es más que un fluir constante, y los conceptos que utiliza el hombre para referirse a ella es a causa del engaño de su intelecto. De esta manera la vida se manifiesta en las cosas individuales, mientras que es el hombre quien busca agruparla en géneros para lograr comprenderlos. Así hay un cierto grupo de seres a los cuales se llama hombre, y dentro de ellos se los vuelve a clasificar de diferentes maneras, según su sexo, color de piel, edad, cultura, religión, etc. Cuando en realidad no son más que realidades particulares en donde se manifiesta

\footnotetext{
${ }^{38}$ NIETZSCHE, Friedrich. Sobre verdad y mentira en sentido extramoral. Op. cit., p. 22.

${ }^{39}$ NIETZSCHE, Friedrich. Sobre verdad y mentira en sentido extramoral. Op. cit., p. 24.

${ }^{40}$ NIETZSCHE, Friedrich. Sobre verdad y mentira en sentido extramoral. Op. cit., p. 24.
} 
la vida. Pero la necesidad del hombre de querer dominar y controlar, lo lleva a agruparlos, definirlos y así segmentizar el flujo de vida.

El lenguaje es el camino por el cual pensamos, es nuestro intelecto. Es éste el que nos engaña, pero es el que nos hace formular teorías o, en este caso, pensar sobre la vida. Si Nietzsche planteó la vida como devenir fue por su intelecto, y lo que él logró derivar de su lenguaje. Así llegó a dilucidar el problema de la voluntad de poder y del eterno retorno dentro de la vida. Es decir que fue gracias al lenguaje, y por culpa del mismo, que Nietzsche se pronunció como lo hizo. Es de esta manera que creemos que se traslada el problema de la vida a los filósofos contemporáneos. No tanto por lo que definió o desarrolló Nietzsche, puesto que nunca dio un concepto acabado; sino más bien por el problema de pensar y expresar dentro de un lenguaje que nos limita. Así, las concepciones que posean los biopolíticos de la vida, se verán con la dificultad de poder definirlos con la limitación propia del intelecto y del lenguaje. Toda definición que se intente dar estará condicionada, y es por esto que los filósofos se detienen en intentar explicar los conceptos, puesto que deben luchar con los límites propios que trae el lenguaje.

\section{La Biopolítica}

Para lograr analizar cómo el lenguaje es un límite según Nietzsche al momento de desarrollar el tema de la vida y cómo esto implica directamente en dos autores contemporáneos, como lo son Agamben y Espósito, se empezará aquí por describir brevemente qué es la biopolítica, y qué papel juega en ella la vida.

El término en sí hace alusión a la vida de las poblaciones, queriendo diferenciarse de esta manera de la vida de los individuos, como sujetos particulares. Esta diferenciación se debe a las políticas que los Estados empezaron a ejercer a partir de la modernidad, en la cual sus propósitos eran principalmente poder controlar las poblaciones. De esta manera todas las actividades de un Estado estaban orientadas al control y la disciplina, no tanto de los individuos, sino ya en un nivel poblacional. Todo esto fue muy estudiado y desarrollado por el filósofo francés Michel Foucault, a quien Mónica Cragnolini cita en su obra asegurando que él "señaló que la biopolítica es aquel 
tránsito de organización de la vida del Estado por el cual la política deja de ocuparse de los cuerpos individuales y pasa a ocuparse de la vida de las poblaciones" ${ }^{41}$. En este sentido se podría ver como un cambio de paradigma, donde pasamos de un Estado preocupado por la disciplina del cuerpo individual, al de un Estado que se preocupa por la vida de la población en su totalidad.

Ahora bien, la pregunta sería cómo se logra controlar la vida de la población. Pues bien, el Estado se encarga de hacerlo a través de "el fomento de la salud, la gestión de trabajo, etcétera" ${ }^{42}$. Es decir que es el Estado quien empieza a hacerse cargo de las distintas esferas en las cuales se desenvuelve cada individuo, para lograr el control de ellos. En este sentido, el ámbito de la salud se vuelve indispensable, pues a través de él se empieza a tener datos de la mortalidad y natalidad de la población, así como de las enfermedades y los niveles de vida, por lo cual se crean grandes registros y de esta manera es posible operar en consecuencia a lo que estos detectan. Además de eso, hay otra razón que señala Foucault como característica propia de la biopolítica y es que "logra unificar lo que sería el cuidado de sí con el cuidado y control del otro; el individuo implicado tiene que considerar que aquello que representa su sometimiento implica un beneficio para él” ${ }^{\prime 3}$. Sólo si el individuo asume ese sometimiento como un bien propio es posible que el Estado se encargue de la vida de la población, de lo contrario todo intento sería vano.

Teniendo estas breves consideraciones, se continuará ahora el desarrollo de los autores propuestos, a saber Agamben y Esposito, para desarrollar el tema de la vida en ellos y, más adelante, cómo está limitada por el lenguaje, siendo así el momento en el que se podría ver la influencia nietzscheana. Es importante tener en cuenta que el desarrollo de estos autores está introducido dentro de la problemática de la biopolítica, y es por esto que realizan una conceptualización detallada de la vida y de sus relaciones con la política y el derecho, puesto que son éstos los que debieran velar

\footnotetext{
${ }^{41}$ CRAGNOLINI, Mónica. "El debate actual en torno a la biopolítica: dos ontologías en disputa”. En: Psicoanálisis de las Configuraciones Vinculantes. Tomo 32, № 2, 2009, p. 190.

${ }^{42}$ CRAGNOLINI, Mónica. "El debate actual en torno a la biopolítica: dos ontologías en disputa”. Op. cit., p. 190.

${ }^{43}$ CRAGNOLINI, Mónica. "El debate actual en torno a la biopolítica: dos ontologías en disputa”. Op. cit., p. 191.
} 
por la vida de la población. Una vez logrado esto, se pasará a ver en qué punto es posible encontrar la relación con el lenguaje y la mirada de Nietzsche.

\subsection{Concepciones de la vida en Agamben y Esposito.}

Tanto Agamben como Esposito entienden a la vida con algunas particularidades, y hacen diferencias entre lo que es la vida humana y la vida de los demás seres vivos, sin perder en cuenta que el hombre también es un ser vivo en cuanto a su aspecto biológico. Por lo tanto lo que se pretende hacer aquí es poder desarrollar cada una de sus concepciones de la vida.

Agamben trae nuevamente la distinción que realizaban los griegos en cuanto al término vida, ya que estos tenían dos conceptos distintos para poder diferenciar; por un lado estaba "zoé, que expresaba el simple hecho de vivir común a todos los seres vivos (animales, hombres o dioses) y bíos, que indicaba la forma o manera de vivir propia de un individuo o grupo" ${ }^{44}$. Una distinción que con el tiempo se fue perdiendo y que, en la actualidad, ambos términos fueron reemplazados por el concepto vida, que abarca dichas acepciones. Agamben también hace un recorrido por diferentes términos y conceptos que utilizaban los griegos, tanto en la filosofía como en la vida cotidiana, pero lo interesante es saber que siempre estuvo latente una distinción entre la vida común a todos y la forma de vida específica.

Para lograr plasmar su pensamiento recurre a un término que será central, el de nuda vida, que según el mismo Agamben significa "la vida a quien cualquiera puede dar muerte pero que es a la vez insacrificable del homo sacer" ${ }^{\prime 4}$. Es la vida sin más, aquello que representa la vida humana despojada de todo lo que podríamos llamar excedente. Pero al mismo tiempo no es la vida como sinónimo de los demás seres, como vida simplemente biológica o corpórea. Esta nuda vida se presenta en el estado de excepción, donde el único derecho que hay es el que posee el soberano sobre ella, ya que el hombre se 'desnuda' frente al poder y a la decisión de matar o dejar vivir que sólo el soberano tiene. Pero Agamben desarrolla también un segundo concepto, que es el de forma-de-vida, con el cual se designa "una vida que no puede separarse nunca

\footnotetext{
${ }^{44}$ AGAMBEN, Giorgio. Homo Sacer I. El poder soberano y la nuda vida. Valencia, Pre-textos, 2006, p. 9.

${ }^{45}$ AGAMBEN, Giorgio. Homo Sacer I. El poder soberano y la nuda vida. Op. cit., p. 18.
} 
de su forma, una vida en la que no es nunca posible aislar algo como una nuda vida” ${ }^{\prime 46}$. Por lo tanto ya aquí no se pueden hacer distinciones por el mero hecho de compartir la vida, sino que son inseparables, ya que en cada instante se pone a prueba su vivir, en su forma va implícita la posibilidad de vivir, además de su felicidad. Por esto, la formade-vida sólo le cabe al hombre, puesto que es el único ser que posee esta posibilidad, y el único que puede aspirar a la felicidad.

Por su parte, Roberto Esposito también tiene en cuenta el concepto de nuda vida y de vida biológica, como centrales a la problemática biopolítica. Pero en el caso de este filósofo no es el término en sí lo que se quiere rescatar en este momento, sino más bien en cómo dicho concepto se relaciona principalmente con la política, y el nuevo paradigma que allí plantea el autor. Es en esta relación que se genera entre la vida y la política donde nace la biopolítica, suceso que para Esposito se da en simultáneo. "El derecho está en necesaria relación con la vida misma de la comunidad" ${ }^{\prime 7}$, puesto que su tarea es la de cuidar la convivencia entre los hombres, que naturalmente tienden a pelearse entre ellos. De lo anterior se desprende que el derecho posee un "rol inmunizador: como sucede en el ámbito bio-médico respecto del organismo humano, garantiza la supervivencia de la comunidad en una situación de peligro mortal. Protege y prolonga la vida de esta, quitándola del alcance de la muerte que acecha" ${ }^{48}$. Esto quiere decir que la política se relaciona con la vida humana de manera protectora, intentando salvaguardar aquello que el mismo hombre busca matar, es decir, al otro, al diferente a sí mismo.

Otra característica importante de la vida que se podría desprender de lo trabajado en Esposito, es su relación con la muerte. Dependiendo de esto se pueden llegar a dos caminos diferentes. Por un lado hay una biopolítica negativa, en la cual hay una política sobre la vida donde lo que predomina es la violencia, y por otro lado una biopolítica positiva, donde hay una verdadera política de la vida. A muerte y vida "las une un vínculo que sujeta la vida a la muerte en la medida en que hace de la muerte el instrumento de conservación de la vida. [...] Sólo una vida que presupone la muerte

\footnotetext{
${ }^{46}$ AGAMBEN, Giorgio. Medios sin fin. Notas sobre la política. Valencia, Pre-textos, 2001, p. 13.

${ }^{47}$ ESPOSITO, Roberto. Immunitas. Protección y negación de la vida. Buenos Aires, Amorrortu, 2005, p. 35.

${ }^{48}$ ESPOSITO, Roberto. Immunitas. Protección y negación de la vida. Op. cit., p. 35.
} 
puede durar más allá de su término natural” ${ }^{49}$. La muerte está siempre en el horizonte de la vida humana, la rodea y es su verdadero límite. No es posible el actuar humano por fuera de esa barrera que se le presenta, hasta allí llega.

Teniendo estas pequeñas consideraciones sobre el concepto de nuda vida en Agamben, y cómo el derecho juega un papel inmunizador en la vida comunitaria según Esposito, es que se cree posible desarrollar la conexión con aquella afirmación de Nietzsche donde dice que el lenguaje es el límite de la vida.

\subsection{Influencia de la concepción nietzscheana de la vida en Agamben y} Esposito.

Se había dicho que la vida según Nietzsche es un flujo continuo, que no tiene separaciones ni está segmentada. Y lo principal de esa noción de vida es que es un devenir, que está siempre por llegar; pero dentro de esto se encuentra el hecho de que esta vida es voluntad de poder, donde aquel que se imponga será quien podrá crear el mundo a su alrededor, y someter a quienes haya vencido. Y como es voluntad de poder se puede decidir sobre qué hacer con ella, pero se debe elegir correctamente, puesto que las acciones del hombre se repetirán infinidad de veces en el tiempo, ya que se manifiesta en un eterno retorno, donde todo vuelve a suceder una y otra vez. Frente a este panorama es que declara Nietzsche que hay demasiadas cosas que el hombre no puede conocer, es más, no puede llegar a comprender qué es la cosa en sí. Pero como no puede vivir comunitariamente sin ciertas seguridades debe inventar la verdad por medio de su intelecto. Es aquí que se introduce la mentira humana, que es justificada y creada por el lenguaje, que lo único que hace es ser un límite para la vida del hombre. Un límite porque demuestra hasta dónde es capaz de llegar, y donde no puede comprender o dominar, inventa conceptos y términos. Es a través de ellos que le pone nombre a sus acciones, a los seres vivos y a toda la vida en sí, creando de esta manera segmentos de algo que no es más que un flujo constante.

Mónica Cragnolini afirma que en la Enciclopedia del pensamiento político de Esposito y Galli, la biopolítica está relacionada con tres cuestiones, a saber: la vida

\footnotetext{
${ }^{49}$ ESPOSITO, Roberto. Immunitas. Protección y negación de la vida. Op. cit., p. 52.
} 
biológica; la nuda vida; y la vida humana en tanto ser viviente ${ }^{50}$. Es decir que gira en torno a la vida, pero al mismo tiempo pareciera ser en torno a tres cosas distintas. $Y$ claramente tienen sus diferencias y de allí que sean conceptos distintos. Pero es aquí donde se introduce la problemática del lenguaje planteada por Nietzsche. El intelecto es el límite para el humano, y éste queda obligado a inventar nuevos términos y palabras para intentar definir aquello que no conoce. Se podría decir que, para el hecho de la vida en tanto flujo continuo que propone Nietzsche, es necesario para los filósofos contemporáneos crear nuevos conceptos, logrando de esta manera clarificar aquello que desean expresar. Sin embargo no están más que poniendo barreras y segmentos al mismo suceso: la vida. Ésta es dividida entre biológica, vida desnuda y vida humana, pero al final de cuentas es el mismo flujo que transcurre por el ser vivo.

En este sentido se puede sostener que el lenguaje es central en todo intento de hacer filosofía, ya que si el lenguaje mismo es nuestro intelecto como sugiere Nietzsche, es imposible realizar algo por fuera de él, ya que dentro de él no se logra esquivar el error y el engaño ${ }^{51}$. Por lo tanto, todo intento por clarificar un tema, por detallarlo introduciendo nuevos conceptos para de esta manera ser más específicos, lo único que genera es crear términos que no reflejan más que los propios límites del ser humano. Tanta precisión en conceptos por intentar ver y explicar la cosa en sí no es más que un engaño del intelecto, una artimaña del lenguaje que se encarga de colocar los argumentos necesarios para que todo el esquema tenga lógica y sentido interno, pero al fin de cuentas la cosa en sí no está allí, no es eso que el hombre creó, por más detallado que pueda estar. La vida es sólo un flujo que no tiene partes ni divisiones, que no se preocupa en demostrar notas esenciales en cada estado o forma que posee, sino que cuando eso sucede es porque se hace presente el hombre con su poder de abstracción y busca encontrar aquello que es parecido o estable en ciertos momentos para darle un nombre específico, para conceptualizar y de esta manera encerrar aquello que intenta comprender.

\footnotetext{
${ }^{50} \mathrm{Cfr}$. CRAGNOLINI, Mónica. "El debate actual en torno a la biopolítica: dos ontologías en disputa”. Op. cit.

${ }^{51}$ Cfr. NIETZSCHE, Friedrich. Sobre verdad y mentira en sentido extramoral. Op. cit.
} 
Anteriormente se nombró la distinción entre bíos y zoé que poseían los griegos, y que Agamben retomó para poder desarrollar su pensamiento en torno a la vida. Desde esa época se puede ver cómo el hombre se preocupó por lograr divisiones para poder explicar con mayor precisión las diferencias que su intelecto le iba mostrando al detenerse a pensar. Ya los griegos buscaron separar en partes la vida, lograr diferenciar la vida común a todos los seres vivos de la vida específica de un grupo, ¿pero acaso no es sólo un engaño, producto del lenguaje, para facilitar la comprensión de un suceso que fluye libremente? Si se toma la postura del flujo continuo y se busca no dividir a través de la invención de conceptos, es probable que el hombre no lograse desarrollar tantas teorías o pensamientos a lo largo de tantos siglos, y al mismo tiempo pareciera imposible lograr expresar o comunicar aquello que le sucede al ser humano si éste no tiene la posibilidad de diferenciar o especificar en los distintos momentos o sucesos.

“El ingreso de la zoé en la esfera de la polis, la politización de la nuda vida como tal, constituye el acontecimiento decisivo de la modernidad, que marca una transformación radical de las categorías político-filosóficas del pensamiento clásico" ${ }^{52}$. Aquí pareciera mostrarse claramente lo que se viene desarrollando sobre el lenguaje. Se puede tomar a la vida como tal, pero sólo una parte de esta vida, aquella que es denominada como zoé, es la que ingresa a la polis y se transforma en un acontecimiento determinante para la historia. Sólo una parte de la vida, aquella que tiene ciertas características que el hombre logró descubrir en ella por medio de su intelecto, sólo ella es la que al introducirse genera un cambio. Esta transformación se da en lo que el autor define como categorías político-filosóficas, que son a su vez otros conceptos creados por el lenguaje humano para detallar ciertas características de una época específica. Sin embargo, esto no es más que una división del flujo que simplemente sucede, y que no tiene causas y efectos, sino simplemente un transcurrir continuo, sin partes o segmentos. La nuda vida así pasa a ser un concepto creado por el lenguaje para lograr clarificar aquello que en realidad el hombre no logra explicar,

\footnotetext{
${ }^{52}$ AGAMBEN, Giorgio. Homo Sacer I. El poder soberano y la nuda vida. Op. cit., p. 13.
} 
aquello que no conoce, pero que sin embargo con el nuevo concepto se hace evidente para todos.

Si bien Agamben realiza una analogía entre la nuda vida y la política por un lado, comparándolo con el hombre en cuanto viviente y el lenguaje por el otro ${ }^{53}$, es evidente que no toma a éste último en los términos de Nietzsche, como un límite. Más bien pareciera ser todo lo contrario, pues lo propone como el medio para lograr llegar a nuevos límites, como aquello que ayuda al ser humano a comprender, entender y de esta manera avanzar en la vida. Pero esta es una diferenciación que no tendrá desarrollo aquí, ya que no es la intención del presente trabajo, si bien pareciera oportuno nombrar esta diferenciación que se produce en cuanto a un concepto central de este escrito.

En lo que respecta a Esposito sucede algo similar, con la excepción que ya se ha aclarado con anterioridad en que no será el concepto de vida en sí lo que se trabajará aquí, sino más bien aquél otro que incide de manera directa, como lo es el término de inmunización. Este concepto es traído del ámbito de la medicina, ya que pareciera ser que el autor no encuentra mejor manera de expresar aquello que quiere decir sino a través de un término ajeno a su campo de estudio. El lenguaje en este aspecto le genera un problema a Esposito, necesita recurrir a una definición que se utiliza en otro ámbito para poder explayarse. En este sentido el lenguaje se convierte en un verdadero límite para el filósofo, y lo resuelve introduciendo la inmunización. Si no fuera por esto tal vez no podría sostener aquello que estaba queriendo investigar. Pero si aquí se vuelve a Nietzsche ocurre que se descubre el engaño del intelecto humano, que lo que genera es acomodar un término existente para que la estructura abstracta que se está creando tenga coherencia lógica y sentido interno. De esta forma pareciera ser que el autor logra un gran hallazgo para su filosofía, y sin embargo puede ser tomado desde una postura nietzscheana como un engaño del intelecto, producto de la limitación que genera el lenguaje.

Ahora bien, se ha dicho que Esposito propone un vínculo particular entre la vida y la muerte, donde se podría afirmar que la muerte es el límite de la primera, y que por

\footnotetext{
${ }^{53}$ Cfr. AGAMBEN, Giorgio. Homo Sacer I. El poder soberano y la nuda vida. Op. cit.
} 
esto es necesario presuponer la propia muerte para llegar más allá del final ${ }^{54}$. En este sentido el autor está conceptualizando el final de la vida, está poniendo un nombre propio a la muerte, aquello a lo cual ningún hombre puede conocer ni saber qué hay más allá. Está inventando una palabra allí donde el intelecto ya no llega, donde Nietzsche nos dice que ya el ser humano no puede conocer ni entender, y por lo tanto lo conceptualiza, lo encierra en ese concepto para engañarse y creer de esta manera que es capaz de poseerlo y dominarlo.

Tanto Agamben como Esposito realizan sus obras y pensamientos en torno a la problemática de la biopolítica, y desarrollan su filosofía alrededor de la temática de la vida, y cómo ésta tiene distintas características y estados, donde no es lo mismo la vida biológica de todos los seres vivos que la vida específica del ser humano. Lo que se intentó realizar aquí fue una crítica desde el punto de partida de que la vida no tiene partes ni segmentos, sino que es un flujo continuo que se desarrolla y se mueve, siendo únicamente el ser humano el que, a través de su intelecto y del lenguaje, la divide a merced de sus necesidades y gustos. Lo que logra de esta manera es un cierto consenso que llama verdad en torno a lo que para él es la vida, y de cómo debiera ser o actuar en consecuencia.

\section{Conclusiones}

La hipótesis que se planteó fue que la concepción nietzscheana de la vida es un flujo continuo imposible de ser segmentado en ninguno de sus ámbitos, debiendo ser retirado el lenguaje de ella, puesto que operaría como un límite más a ese flujo. Pero al mismo tiempo es el lenguaje la herramienta que poseen los filósofos biopolíticos para definir la vida que se pone en juego en la población. Si se detiene en lo trabajado en el primer y segundo capítulo de este trabajo, se puede observar que se desarrolló el concepto de vida según Nietzsche y se demostró por qué el lenguaje es un límite para ella, para aquel flujo continuo que no conoce de divisiones o partes. Sin embargo es el hombre el que, por medio del intelecto, la diferencia en secciones y segmentos según su parecer. Se puede afirmar que para Nietzsche es imposible siquiera pensar por

\footnotetext{
${ }^{54}$ Cfr. ESPOSITO, Roberto. Immunitas. Protección y negación de la vida. Op. cit.
} 
fuera del lenguaje, y aquí venía el problema de cómo hacer la filosofía. Pues bien, simplemente pareciera no haber una salida. El propio filósofo no esboza nada mas, puesto que hacerlo también sería realizarlo desde el lenguaje, el cual sólo puede engañar y no deja conocer al hombre la cosa en sí. Si bien Nietzsche desarrollará otro camino en torno a la estética para llegar a ese objetivo, sostiene que el lenguaje no es una ayuda para tal fin.

A su vez, el lenguaje es la herramienta de todo filósofo a la hora de plantear su pensamiento, y ninguno puede escapar de hacerlo a través de él. Por esto, tanto Agamben como Esposito definen a la vida intentando clarificar lo más posible el lenguaje que utilizan, para no dejar lugar a la duda o confusiones, y es así que introducen nuevos conceptos que los ayuden a desarrollar su filosofía. La intención que se llevó adelante en el último capítulo fue justamente una crítica desde el punto de vista nietzscheano en cuanto al lenguaje en sí, y quedó demostrado que ninguno de los dos filósofos lo tuvo en cuenta a la hora de llevarlo adelante. El lenguaje así pasó a ser un límite de la vida, puesto que gracias a él, tanto Agamben y Esposito lograron dividir la vida en varias partes, diferenciando las distintas secciones y relacionándolas, dejando claramente de lado la idea del flujo continuo que propone Nietzsche.

En consecuencia de todo esto se puede decir que el principal objetivo que se planteo en este trabajo se logró alcanzar, que era el de poder desarrollar la concepción de vida en Nietzsche para lograr determinar cuál es la importancia dentro de su pensamiento filosófico y qué impronta dejó para la filosofía posterior. Claramente la vida tiene un lugar de privilegio, siendo que en reiteradas ocasiones lo retoma. $Y$ teniendo en cuenta sobre todo que, temas tan centrales como el eterno retorno y la voluntad de poder, están ligadas y se plasman en la vida. Es innegable el lugar central que ella adquiere, por más que el filósofo, fiel a su estilo, nunca dio una definición exacta, ya que esto sería utilizar de mala manera el lenguaje. Seguido de esto el otro objetivo planteado queda también resuelto, ya que se demostró que el lenguaje opera como un límite para la vida según la concepción nietzscheana, puesto que intenta delimitarla y apresarla, sin dejar que se exprese según su voluntad. No hay manera de 
entender el lenguaje en Nietzsche si no se lo considera como un límite y un perfecto engañador del ser humano.

En cuanto al tercer objetivo, el de examinar si esta concepción nietzscheana de la vida se encuentra presente o tiene alguna influencia en las concepciones de vida de los filósofos de la biopolítica contemporánea, queda en claro que no es así, ya que tanto Agamben como Esposito no poseen la misma noción que Nietzsche en cuanto a la vida, no la toman como un flujo continuo. Y mucho menos consideran a la vida como limitada por el lenguaje; como se expuso en el desarrollo, el mismo Agamben tiene una noción de lenguaje totalmente contraria a esta visión. De esta manera se ve que la noción nietzscheana de la vida no influye en la filosofía de los pensadores de la biopolítica.

Ahora bien, lo interesante de esto es poder observar cómo una postura nietzscheana de la vida y el lenguaje sigue trayendo críticas a los desarrollos actuales de la filosofía. Si el lenguaje sólo engaña y confunde al ser humano para poder decir que existe algo como verdadero cuando en realidad no lo es, tal vez no haya manera de realizar ninguna filosofía o pensamiento. Por esto el mismo Nietzsche hizo silencio y no pudo avanzar en este sentido, haciendo caso omiso de sus propias ideas y utilizando el lenguaje para poder llevar adelante la crítica más grande que se había realizado hasta el momento frente a la edad moderna. Puesto que es evidente que lo logró a través de su pensamiento y mirada crítica de la vida que lo rodeaba, pero que debió recurrir al mismo lenguaje, dejándose guiar por el mismo intelecto que tanto se esforzó en criticar. 